\title{
Single-Port Laparoscopic Splenectomy as an Alternative for Conventional Laparoscopic Splenectomy
}

\author{
Ahmed Gamal El-Din Osman, MD, MRCS; Emad Abdellatief Daoud, MD; MRCS \\ Department of General Surgery, Ain Shams University, Cairo, Egypt
}

Introduction: Laparoscopic splenectomy is developing as the gold standard for the management of splenic disorder. The concept of minimal-invasive surgical techniques has progressed since the early 1990s from the standard multiport laparoscopy to the natural orifice transluminal endoscopic surgery and recently, to single-port laparoscopic surgery.

Aim: To assess the feasibility and safety of transumbilical single port laparoscopic splenectomy.

Patients and methods: Between September 2013 and August 2016, transumbilical single-port splenectomy was performed on 13 patients via a $2.5 \mathrm{~cm}$ curved incision at the lower umbilicus edge, and special single incision laparoscopic surgery $\left(\right.$ SILS $^{T M}$ ) port (Covidien, Mansfield, MA) was introduced through which splenectomy was done.

Results: A total of fifteen patients underwent minimally invasive splenectomy. There were 3 conversions to multiport laparoscopic splenectomy. The operative time was (123.07士16.7).

Conclusion: Single port laparoscopic splenectomy is safe and feasible and could be a logical alternative to classical laparoscopic splenectomy.

Key words: Single port, laparoscopy, splenectomy.

\section{Introduction}

Laparoscopic procedures have been generalized to become a safe and effective surgical approach since Georg Kelling's first laparoscopic procedure on dogs (1902) and Hans Christian Jacobaeus's first report of a laparoscopic operation on human beings (1910). ${ }^{1}$ Conventional laparoscopic splenectomy has been first described and performed since the early 1990 s by Delaitre and Maignien. ${ }^{2}$ Today, laparoscopic splenectomy (LS) has become the standard of care for routine splenectomy and it requires an average 4 trocars (range 5-7)..$^{3,4}$ LS offers many advantages compared with the open procedure as less blood loss, shorter hospital stays with decreased narcotic requirement, quick return of bowel function and early return to daily activities within 2 weeks. ${ }^{5-8}$ The most common indications for laparoscopic splenectomy worldwide are immune thrombocytopenic purpura (ITP), and hereditary spherocytosis. - $^{-12}$ Over the course of time, the technique has advanced and several surgeons have introduced different types of laparoscopic procedures such as a single-port laparoscopic surgery, a hand-assisted laparoscopic surgery, and a reduced port laparoscopic surgery. ${ }^{13-15}$ The current trend is to improve the cosmoses when applying minimally invasive procedures if feasible, and single-port surgery is one of the options to achieve this goal. ${ }^{16-18}$ We aim from this study to assess the feasibility and safety of transumbilical single port laparoscopic splenectomy as an alternative to standard laparoscopic splenectomy.

\begin{abstract}
Patients and methods
Between September 2013 and August 2016 a total of 15 patients had undergone Single port splenectomy (SPS) in Ain shams University Hospital. The indication for splenectomy included various hematological disorders (idiopathic thrombocytopenic purpura, hereditary spherocytosis, autoimmune hemolytic anemia) without past history of previous upper abdominal surgery, uncorrected coagulopathies, severe portal hypertension from liver cirrhosis, marked splenomegaly and morbid obese patients with a body mass index (BMI) greater than $40 \mathrm{~kg} / \mathrm{m}^{2}$ were excluded from the study. All patients were informed about the technique and had signed informed consent form. Patients were evaluated for age, gender, BMI, diagnosis, pre-operative complete blood counts, work-up for coagulopathy and CT pelvi/abdominal to determine the dimensions of the spleen, which were recorded by the maximum length in the coronal and axial planes and searching for susceptible accessory spleens. All patients were injected with vaccines against Haemophilus Influenzae type B, pneumococcus and meningococcus at least two weeks before the elective splenectomy.
\end{abstract}

Prednisolone IV ( $1 \mathrm{mg} / \mathrm{kg}$ ) was given preoperatively to ITP patients to decrease the incidence of 
bleeding and $1 \mathrm{~g}$ intravenous ampicillin-sulbactam was given before the operation and every 12 hours along their hospital stay.

The patients were operated on under general anesthesia with the application of Foley catheters, nasogastric tube, and compression stockings. The patients were placed in the right lateral decubitus position in a standard fashion and tilted at a $15^{\circ}$ reverse Trendelenburg position and bent at the umbilicus, increasing the distance between the iliac crest and costal margin. The abdominal cavity was insufflated with a Veress needle through a $2.5 \mathrm{~cm}$ curvilinear incision at the lower edge of the umbilicus. Special single incision laparoscopic surgery (SILS) port (Covidien) (Figure 1) was introduced with a sponge holder from same fascial opening. The ultrasonic scalpel (Harmonic ACE, Ethicon Endo-Surgery) and the 12-mm endovascular stapler (Ethicon Endosurgery) were used for ligating and dissecting the vessels (Figure 2B), firstly, a long shaft 5 $\mathrm{mm}$ telescope with $30^{\circ}$ angle was introduced, and two articulated hand instruments were used to explore the whole abdominal cavity for accessory spleens. Then articulated $5 \mathrm{~mm}$ grasper (Figure 2A) was inserted and held in the left hand, and $5 \mathrm{~mm}$ harmonic scalpel was inserted and held by the right hand of the surgeon. The diaphragmatic attachments had significant importance for counter-traction by hanging the spleen upwards with the help of gravity. We obeyed the inferior to the superior dissection rule and we started with the mobilization of the splenic flexure. After the liberation of the lower pole of the spleen, the gastro-splenic ligament was divided by harmonic scalpel. The hilum was exposed, and prepared and splenic vessels were ligated with one or two 12$\mathrm{mm}$ endovascular staplers. After that, the table was tilted left, and the retrosplenic ligaments were liberated. The short gastric vessels were dissected by using an ultrasonic scalpel. The liberated spleen was inserted into a special sterile retrieval bag which was morcellated before removal through the umbilical incision. A suction drain was placed in the operative field routinely after splenectomy. The SILS trocar was removed, the abdomen was deflated, the fascial defect was sutured with nonabsorbable suture material. Oral intake and fluids were commenced and progressed as tolerated. Typically, nonsteroidal anti-inflammatory drugs and narcotics were used for analgesia if there were no hematologic contraindications. Data related to the operation (operative time, estimated blood loss $(E B L)$, incidence and indications for conversion), duration of hospital stay and post-operative complication were recorded.

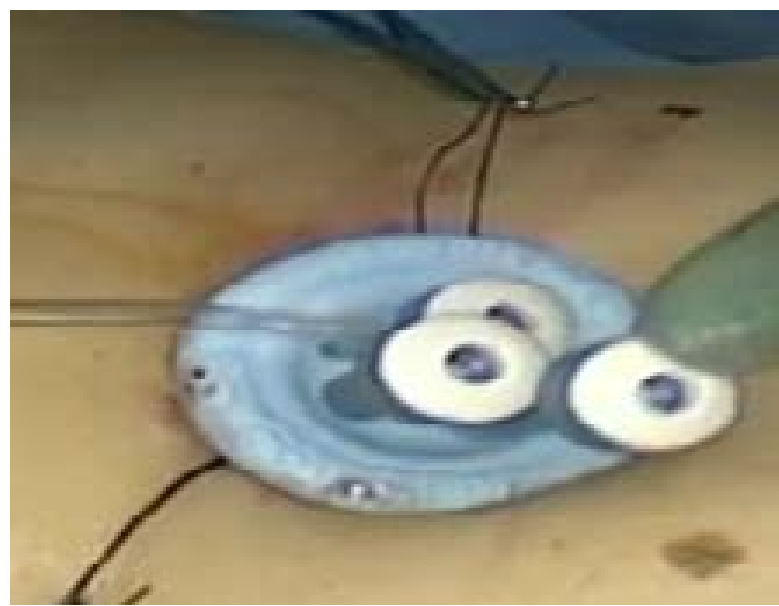

Fig 1: SILS port inserted through $2.5 \mathrm{~cm}$ curvlinear incision.
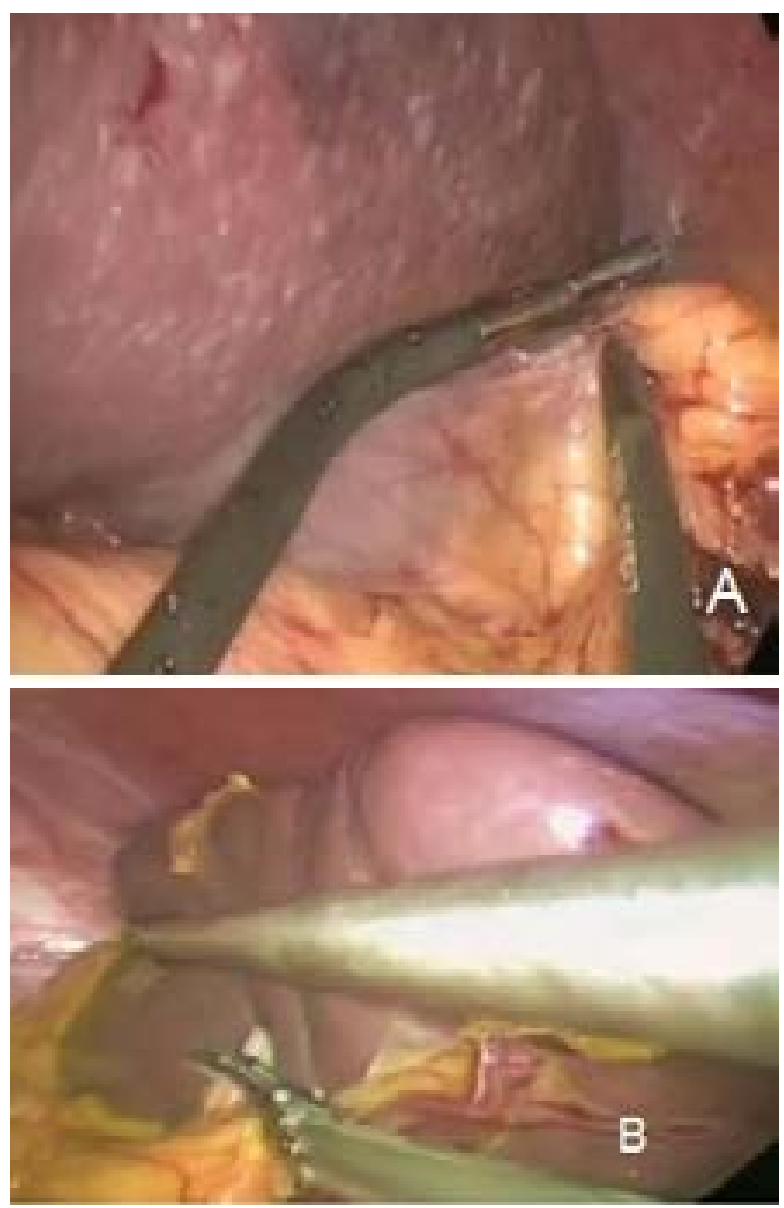

Fig 2A: Articulating instrument; 2B: Ultrasonic scalpel dissecting gastrosplenic ligament.

Data was expressed as a mean \pm standard deviation. All statistical analyses were evaluated by PASW Statistics ver. 18.0 (SPSS Inc., Chicago, IL, USA). The statistical significance was set at $P \geq 0.05$ was insignificant. The analysis was performed with the statistical package. ${ }^{19}$

\section{Results}

Thirteen patients were included in this study; 9 
women and 4 men with a mean age of $(36.6 \pm 13)$ years and mean BMI $27.3 \pm 2.5$ (Table 1).

The mean dimension of the spleen was $113.2 \pm 24.3$ in axial section and $113.2 \pm 24.3$ in coronal section with 4 cases out of 15 with minimal splenomegaly (Table 2). The indications for splenectomy were refractory chronic ITP in 10 patients, hereditary spherocytosis in 3 patients and 2 patients with autoimmune hemolytic anemia (Table 3). All patients had no prior upper abdominal surgery.

Table 1: Demographic data

\begin{tabular}{ll}
\hline Characteristic & SPLS \\
\hline Age & $36.6 \pm 13$ \\
Male/female & $4 / 11$ \\
BMI & $27.3 \pm 2.5$ \\
\hline
\end{tabular}

Table 2: Radiological dimensions of the spleen by CT

\begin{tabular}{lc}
\hline Radiological dimension of spleen in $\mathbf{( m m )}$ \\
\hline Axial section & $113.2 \pm 24.3$ \\
Coronal section & $120.7 \pm 37.6$ \\
\hline
\end{tabular}

Table 3: Indication for splenectomy

\begin{tabular}{ll}
\hline Causes for splenectomy & \\
\hline ITP & $10 / 15(61.53 \%)$ \\
Spherocytosis & $3 / 13(23.07 \%)$ \\
Autoimmune hemolytic anaemia & $2 / 13(7.69 \%)$ \\
\hline
\end{tabular}

As regards intra-operative results, three patients were converted to multi port laparoscopic splenectomy (MPLS) (2 patients because of bleeding and one patient due to technical difficulty) with no conversion to open surgery. No intra-abdominal organ injury was recorded. The operative time was $(123.07 \pm 16.7 \mathrm{~min})$ and mean estimated blood loss was $260.6 \pm 210.7 \mathrm{ml}$. The mean length of hospital stay was $2.8 \pm 2.3$ days (Table 4) with minimal recorded post operative pain. There was no mortality recorded in this study.

Table 4: Operative outcomes

\begin{tabular}{ll}
\hline Operative outcomes & \\
\hline Operating Time (min) & $123.07 \pm 16.7$ \\
Estimated Blood Loss (ml) & $260.6 \pm 210.7$ \\
Hospital Stay & $2.8 \pm 2.3$ \\
\hline
\end{tabular}

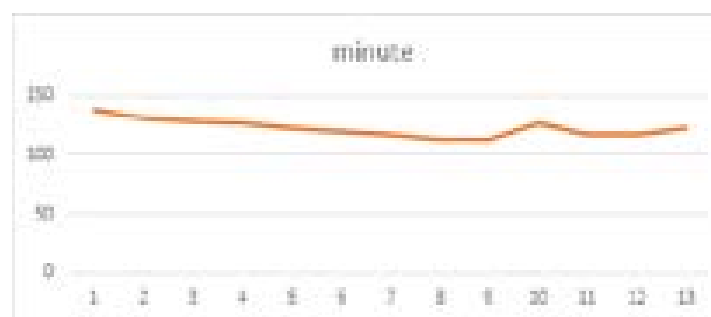

Fig 3: Operating time through the whole study.

The operative time improved due to gaining experience through the whole study starting with 140 min and ending with 104 minutes with mean 260.6 \pm 210.7 min (Table 4) and (Figure 3).

The early postoperative complications rate was $13.33 \%$ ( 2 cases) with one patient developed lung atlectasis and other developed pleural effusion.

The late postoperative complication rate was $13.33 \%$ (2cases) and both of them developed an incisional hernia after 6 months (Table 5).

Table 5: Intra and postoperative early and late complications

\begin{tabular}{ll}
\hline Operative complication & Number \\
\hline Intraoperative complication & \\
Bleeding & $2 / 13(13.33 \%)$ \\
Adjacent Organs Injury & 0 \\
Conversion & $3 / 13(20 \%)$
\end{tabular}

Early post operative complication

$\begin{array}{ll}\text { Atelectasis } & 1 / 13(6.66 \%) \\ \text { Reactionary hemorrhage } & 0 \\ \text { Pleural effusion } & 1 / 13(6.66 \%)\end{array}$

Late post operative complication

Incisional hernia 2/13(13.33\%)

\section{Discussion}

Laparoscopic splenectomy has become one of the most frequently performed laparoscopic solid organ procedures and has gradually replaced conventional laparotomy. ${ }^{20-22}$ As the techniques and instruments had developed, more surgeons had performed laparoscopic single-port surgery for various types of abdominal surgery for better postoperative outcomes such as less pain and reduced scarring. ${ }^{22}$

This study demonstrates single port laparoscopic splenectomy to be a safe and efficient 
alternative to multiport laparoscopic splenectomy with no serious intraoperative complications and no conversion to open splenectomy, our conversion rate to MPLS was $20 \%$. The initial reports for singleincision laparoscopic splenectomy demonstrated a conversion rate from $10^{23}-2516 \%$. One case of our conversions $(6.66 \%)$ occurred early in the study mostly due to lack of experience and two cases (13.335) were converted due to excess blood loss; several studies illustrated that the main cause of conversion, was excess blood loss. ${ }^{24,25}$ In our study, the operative time was (117.4 $\pm 16.7)$ minutes, which were longer than standard laparoscopic splenectomy shown in other studies $(95.9 \pm 38.9 \text { minutes })^{26}$ and $(71.1 \pm 18.1 \text { minutes })^{9}$ due to well-known problems of single port procedures in general as clashing of instruments, loss of triangulation, intra-corporal interference of instruments with each other and camera and uncomfortable positioning between the camera operator and the surgeon. Moreover, the location of the spleen is considered to be a specific obstacle for single port procedures as it is far up embedded in the left sub-diaphragmatic pouch as well as spleen can't be grasped and retracted. These difficulties had prolonged the operative time in our series as other studies which were nearly the same operative time..$^{27,28}$

As regards intraoperative complications, blood loss in our study was $(260.6 \pm 210.7 \mathrm{ml})$ which was nearly the same as other studies; Han $(295.8 \pm 301.3)^{26}$ and Taragarona ${ }^{29}<100 \mathrm{ml}$, two cases suffered from intraoperative bleeding and were converted to MPLS due to inadequate exposure of the hilum. In laparoscopic splenectomy, bleeding from splenic hilum is the most common complication that requires conversion to open splenectomy. ${ }^{9,24,25}$ Therefore a good exposure of splenic hilum is an essential step. We performed our operations by retracting the spleen to the left upper quadrant and starting the dissection from splenocolic ligament to the hilum with articulating instruments without the need of any additional trocars.

In two patients, who required conversion to standard MPLS due to bleeding from splenic hilum without being able to identify the source, once we added extra trocar for appropriate traction, bleeding points were identified and controlled. Several authors had shown their techniques to overcome this problem as Shirikanth ${ }^{30}$ who offered to use a gastric traction suture to provide wider exposure of lesser sac, facilitated the division of short gastric vessels, dissection of the splenic hilum and excellent view of the splenic bed and Misawa et $\mathrm{a}^{23}$ who described the use of the Tug exposure technique in which a cloth tape is introduced intraperitoneally to encircle and provide traction around the splenic hilum. We used a long shaft $30^{\circ}$ camera which enhances the surgeon's extra-corporal movements preventing the interference with the light-source cables to overcome visualization difficulties, especially during the dissection of the posterior attachments as Tarorgona recommended. ${ }^{31}$

The surgeon and the camera operator must form a team and get used to each other in order to make complementary movements in and out-side the patient, in addition to another case converted to MPLS due to technical difficulties.

In our study, the mean length of hospital stay was 2.8 \pm 3.2 days, which was shorter than other studies; Han 26 (5.8 \pm 2.5$)$ days, and Barbaros ( $3 \pm 1$ ) days. ${ }^{32}$ As regards postoperative complication, in our study, there was one case of atelectasis and another case of pleural effusion with no other intraoperative or early postoperative morbidity or mortality.

Two cases $(13.33 \%)$ developed an incisional hernia within 6 months. Port site hernia remains a major defect in SILS. Emmanuel et al ${ }^{33}$ proved in his study that the development port site hernia is a major setback for a single port procedure that is popularized based on its cosmetic superiority. The data regarding whether single-port access is advantageous with regard to postoperative pain is not uniform. Our study showed a difference in patient satisfaction in case of pain sensation. Unfortunately, the number of patients was so small that these results had no statistical significance. Boone $^{34}$ study showed that single-incision patients used a lower total dose of narcotic medication, in comparison to MPLS but this did not reach statistical significance as the study included a low number of patients.

The limitation of this study was as follows; the clinical, esthetic, and functional advantages require further analysis as well as better patient selection criteria if there is a need for standardization of the single port technique.

\section{Conclusion}

Single-port access splenectomy is a safe and feasible alternative to standard multiport laparoscopic splenectomy. It has a clear benefit in terms of enhanced cosmesis. However, there are needs for overcoming the difficulties of single access techniques, namely, the loss of triangulation and collision of the instruments before the standardization of the procedure.

\section{References}

1. Sutherland GA, Burghard FF: The treatment of splenic anaemia by splenectomy. Lancet 1910; 2: 1819-1822. (Cited by Delaitre and 
Maingnien) 2.

2. Delaitre B, Maignien B: Splenectomy by the laparoscopic approach. Report of a case. Presse Med 1991; 20: 2263-2264.

3. Park A, Targarona EM, Trías M: Laparoscopic surgery of the spleen: State of the art. Langenbecks Arch Surg 2001; 386: 230-239.

4. Feldman LS: Laparoscopic splenectomy: Standardized approach. World J Surg 2011;35: 1487-1489.

5. Gamme G, Birch DW, Karmali S: Minimally invasive splenectomy: An update and review. Can J Surg 2013; 56: 280-285.

6. Canes D, Desai MM, Aron M, Haber GP, Goel RK, Stein RJ, et al: Transumbilical single port surgery: Evolution and current status. Eur Urol 2008; 54: 1020-1029.

7. Romanelli JR, Earle DB: Single-port laparoscopic surgery: An overview. Surg Endosc 2009; 23: 1419-1427.

8. Merchant AM, Cook MW, White BC, Davis SS, Sweeney JF, Lin E: Transumbilical Gelport access technique for performing single incision laparoscopic surgery (SILS). Gastrointest Surg 2009; 13: 159-162.

9. Barbarous $U$, Dinccag A: Single incision laparoscopic splenectomy: The first two cases. Gastrointest Surg 2010; 14: 1473-1474.

10. Targarona EM, Gomez C, Rovira R, Pernas JC, Balague $C$, Guarner-Argente $C$, et al: NOTESassisted transvaginal splenectomy: The next step in the minimally invasive approach to the spleen. Surg Innov 2009; 16: 218-222.

11. Moris DN, Bramis KJ, Mantonakis EI, Papalampros EL, Petrou AS, Papalampros AE: Surgery via natural orifices in human beings: Yesterday, today, tomorrow. Am J Surg 2012; 204: 93-102.

12. Habermalz B, Sauerland S, Decker G, Delaitre B, Gigot JF, Leandros E, et al: Laparoscopic splenectomy: The clinical practice guidelines of the European Association for Endoscopic Surgery (EAES). Surg Endosc 2008; 242: 821-848.

13. Winslow ER, Brunt LM: Perioperative outcomes of laparoscopic versus open splenectomy: A meta-analysis with an emphasis on complications. Surgery 2003; 134: 647-653.
14. Moreno-Sanz $C$, Noguera JF, Herrero ML, Morandeira A, Llorente C, Ruíz G, et al: Singleincision laparoscopic surgery. Cir Esp 2010; 88: $12-17$.

15. Targarona EM, Balague C, Trias M: Is the laparoscopic approach reasonable in cases of splenomegaly? Semin Laparosc Surg 2004; 11: 185-190.

16. Targarona EM, Lima MB, Balague $C$, Trias M: Single- port splenectomy: Current update and controversies. J Minim Access Surg 2011; 7: 61-64.

17. Quah C, Ayiomamitis GD, Shah A, Ammori BJ: Computed tomography to detect accessory spleens before laparoscopic splenectomy: Is it necessary? Surg Endosc 2011; 25: 261-265.

18. Bruzoni M, Dutta S: Single-site umbilical laparoscopic splenectomy. Semin Pediatr Surg 2011; 20: 212-218.

19. Statistical Analysis Systems (SAS): User's Guide. 2005, Cary: SAS Institute, Inc, Version 9.

20. Monclova JL, Targarona EM, Vidal P, Peraza $Y$, Garcia F, Otero CR, et al: Single incision versus reduced port splenectomy searching for the best alternative to conventional laparoscopic splenectomy. Surg Endosc 2013; 27: 895-902.

21. Fan $Y$, Wu SD, Kong J, Su $Y$, Tian $Y$, Yu $\mathrm{H}$ : Feasibility and safety of single-incision laparoscopic splenectomy: A systematic review Surg Res 2014; 186: 354-362.

22. Colon MJ, Telem D, Chan E, Midulla P, Divino C, Chin EH: Laparoendoscopic single site (LESS) splenectomy with a conventional laparoscope and instruments. JSLS 2011; 15: 384-386.

23. Misawa T, Sakamoto T, Ito R, Shiba H, Gocho T, Wakiyama S, et al: Single-incision laparoscopic splenectomy using the "tug-exposure technique" in adults: Results of ten initial cases. Surg Endosc 2011, 25: 3222-3227.

24. Mattioli G, Prato A, Cheli M, Esposito C, Garzi A, LiVoti G, et al: Italian multicentric survey on laparoscopic spleen surgery in the pediatric population. Surg Endosc 2007; 21: 527-531.

25. ParkAE, Birgisson G, Mastrangelo MJ, Marcaccio MJ, Witzke DB: Laparoscopic splenectomy: Outcomes and lessons learned from over 200 cases. Surgery 2000; 128: 660-667. 
26. Han ES, You YK, Kim DG, Lee JS, Kim EY, Lee $\mathrm{SH}$, et al: Clinical significance of Singleport laparoscopic splenectomy: Comparison of single-port and multiport laparoscopic procedure; Ann Surg Treat Res 2015; 89: 5560.

27. Malladi $P$, Hungness $E$, Nagle A: Single access laparoscopic splenectomy. JSLS 2009; 13: 601-602.

28. Rottman SJ, Podolsky ER, Kim E, Kern J, Curcillo PG: 2nd. Single port access (SPA) splenectomy. JSLS. 2010; 14: 48-52.

29. Targarona EM, Balague C, Martinez C, Pallares L, Estalella $L$, Trias M: Single port access: $\mathrm{A}$ feasible alternative to conventional laparoscopic splenectomy. Surg Inno 2009; 16: 348-352.

30. Srikanth G, Wasim MD, Sajjad A, Shetty N: Single-incision laparoscopic splenectomy with innovative gastric traction suture. J Minim Access Surg 2011; 7: 68-70.
31. Targarona EM, Pallares JL, Balague C, Luppi $C R$, Marinello $F$, Hernández $P$, et al: Single incision approach for splenic diseases: A preliminary report on a series of 8 cases. Surg Endosc 2010; 24: 2236-2405.

32. Barbaros U, Aksakal N, Tukenmez M, Agcaoglu O, Bostan MS, Kilic B et al: Comparison of single port and three port laparoscopic splenectomy in patients with immune thrombocytopenic purpura: Clinical comparative study. J Minim Access Surg 2015; 11: 172-176.

33. Agaba $E$, Rainville $H$, Ikedilo O, Vemulapali P: Incidence of port-site incisional hernia after single-incision laparoscopic surgery. JSLS 2014; 18: 204-210.

34. BooneBA, Wagner P, GanchukE, Evans L, Evans $\mathrm{S}$, Zeh $\mathrm{HJ}$, et al: Single-incision laparoscopic splenectomy: Preliminary experience in consecutive patients and comparison to standard laparoscopic splenectomy Surg Endosc 2013; 27: 587-592. 